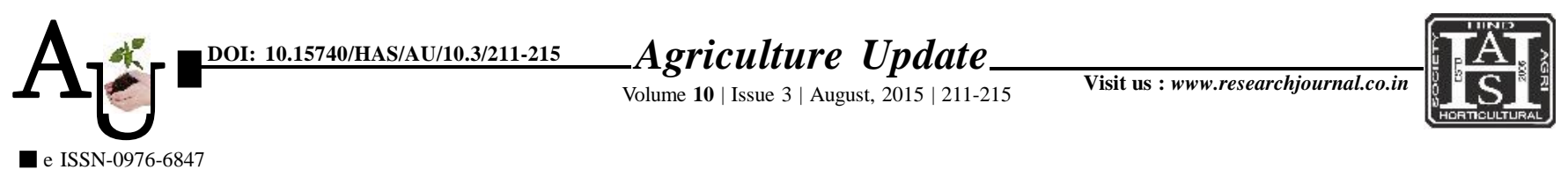

\title{
Research Article: Training for capacity building of extension personnel for improving efficiency of knowledge transfer to farming communities
}

\section{AMTUL WARIS}

Article Chronicle:

Received :

18.04.2015;

Revised :

07.07.2015;

Accepted :

08.08.2015

Key Words :

Training, Capacity

building, Efficiency,

Knowledge, HRD

Author for correspondence :

AMTUL WARIS

Directorate of Rice

Research, Rajendranagar, HYDERABAD

(TELANGANA) INDIA

Email: amtul.waris@

gmail.com
SUMMARY : Training is considered as one of the important tools for human resource development (HRD). It has immense potential in transfer and utilization of latest technical know how, leadership development, organization of people, formation of self-help group mobilization of people as well as resources. Training is, thus, a crucial and continuous requirement for human resource development. Training of extension personnel is highly essential for providing latest technical know-how and also for inculcating competence, professionalism and service morale. The present study relates to the training programs organized for extension personnel from different State Departments of Agriculture of the country. The objective of the training programs was to impart knowledge and skills in the improved livestock and horticulture technologies for livelihood security in dry land and arid areas. Majority of the participants of the livestock and horticulture training course 73.33 and 66.67 per cent, respectively rated it as meeting their expectations. Gain in knowledge levels of trainees was observed after exposure to the training courses. A number of new learning areas were mentioned by the trainees which they found had great applicability in their respective areas and farmers would be motivated to adopt them for improved livelihood security.

How to cite this article : Waris, Amtul (2015). Training for capacity building of extension personnel for improving efficiency of knowledge transfer to farming communities. Agric. Update, 10(3): 211-215. 